\title{
Modeling of traction power supply systems for movement of high-speed trains
}

\author{
Aleksandr Cherepanov ${ }^{1, *}$, Vasily Zakaryukin ${ }^{1}$, and Andrey Kryukov ${ }^{1,2}$ \\ ${ }^{1}$ Irkutsk State Transport University, 664074 Irkutsk, Russia \\ ${ }^{2}$ Irkutsk National Research Technical University, 664074 Irkutsk, Russia
}

\begin{abstract}
Upgrading of traction power supply systems will be required to transfer electrified railway lines to high-speed traffic. Coaxial cables and balancing transformers can be used as technical upgrading means. The article presents the results of computer simulation in the Fazonord software complex of the traditional $2 \times 25 \mathrm{kV}$ traction system, as well as systems with coaxial cables and Woodbridge symmetric transformers. Simulation results showed that the use of cables contributes to a significant increase in the level of voltage on current collectors of electric rolling stock. Use of modified Woodbridge transformers makes it possible to reduce the imbalance coefficient by the reverse sequence on high voltage buses of traction substations. However, the reduction is insignificant and depends on the modes of movement of trains in adjacent inter-station zones. The biggest positive effects occur in the integrated application of balancing transformers and coaxial cables.
\end{abstract}

\section{Introduction}

Currently, railway lines for the traffic speeds of over $160 \mathrm{~km} / \mathrm{h}$ are being operated and built, which are electrified primarily by alternating current [1 - 4]. To ensure efficient power supply for transferring of electrified lines to high-speed traffic, upgrading of the traction network (TN) is required, the purpose of which is to ensure that the voltage levels on the rolling stock current collectors (ERS) lie in the range from 24 to $29 \mathrm{kV}$ in the normal mode of operation [1].

To select rational ways to upgrade the TN for high-speed traffic conditions, computer modeling facilities shall be required for the railway power supply systems (RPSS) modes including three-phase and single-phase subsystems and the systems actively interacting with each other. Availability of such subsystems makes it much more complicated to create an adequate computer model based on traditional approaches to determination of the RPSS modes, which are based on the use of the symmetric components method (SCM) [5-7]. Due to multiple longitudinal and transverse asymmetries in the RPSS, the use of the SCM becomes almost impossible with the formation of models of real systems with thousands of nodal points. It is associated with the algorithmic difficulties caused by the need to take numerous imbalances into consideration. Resolving of this problem is complicated due to

\footnotetext{
*Corresponding author: santela89@mail.ru
} 
the specific nature of the RPSS that consists in the movement of traction loads [5-10], which is particularly pronounced on high-speed lines.

The second problem that arises in simulation of high-speed railways is the use of nontraditional devices, for example, Woodbridge synchronizing transformers and coaxial cables, to strengthen their traction networks [1]. This requires creation of universal modeling technologies that ensure adequate consideration of any amplifying elements that are acceptable in practice.

The objective of the study was to develop the methods and tools that provide adequate simulation of modes of high-speed lines with high gain elements. The proposed simulation methods for the modes are based on the use of phase coordinates and allow adequately simulation of high-speed railways RPSS and choosing the most rational means of their upgrading.

The novelty of the proposed methods is that they are of the multiphase, multi-modal and multitask nature. The first factor provides consideration of multiphase systems: singlephase, three-phase, four-phase, six-phase, and their combinations. The second distinctive feature makes it possible to determine a wide range of modes: normal, emergency, nonsinusoidal, and limiting. The third feature provides solution of additional tasks that are relevant in the practice of design and operation of the RPSS: determination of induced voltages on adjacent power lines; calculation of electromagnetic field strengths created by the TN; parametric identification of power supply lines and transformers; accounting for the proximity effect in simulation of massive current-conducting parts. Another important distinguishing feature of the proposed methods is joint simulation of the traction power supply system and the high-voltage power supply network, which allows implementing a systemic approach to the analysis of RPSS modes of alternating current.

\section{Research methods}

Irkutsk State Transport University (Russia) developed the methods for simulation of RPSS in phase coordinates [11] based on the use of lattice replacement schemes (LRS) of multiconductor elements, which are the RLC elements joined into complete graph schemes. The following formalized determination may be provided for the LRS:

$$
T E C: h u b \cup c o n, \forall i, j \subset h u b \rightarrow c_{i, j} \subset c o n,
$$

where TEC is determination of the LRS; $h u b$ is the totality of nodes; con is the totality of branches. By combining LRS of individual elements, the lattice structure is implemented that corresponds to the three-phase and single-phase network of the RPSS:

$$
T E C_{\Sigma}=\bigcup_{k=1}^{n} T E C_{k},
$$

where $U$ denotes joining of LRS of individual elements on the basis of the specific network topology.

The conducting matrix of the calculation model is formed on the basis of $T E C_{\Sigma}$.

$$
\mathrm{A}: T E C_{\Sigma} \rightarrow \underline{\mathbf{Y}}_{\Sigma}=\mathbf{M}_{0} \underline{\mathbf{Y}}_{V} \mathbf{M}_{0}^{T},
$$

where $\underline{\mathbf{Y}}_{V}$ is the block-diagonal matrix, blocks of which correspond to conductivity matrices of individual elements; $\mathbf{M}_{0}$ is the generalized incidence matrix. Non-linear equations that describe the totality of RPSS modes for movement of trains are formed with the use of $\underline{\mathbf{Y}}_{\Sigma}[11]$ :

$$
\underline{\mathbf{Y}}_{\Sigma}\left(t_{k}\right) \dot{\mathbf{U}}\left(t_{k}\right)=\operatorname{diag} \frac{1}{\widetilde{U}_{j}\left(t_{k}\right)} \cdot \widetilde{\mathbf{S}}\left(t_{k}\right) ; j=\overline{1 . . n} ; k=1 . . m,
$$


where $\dot{\mathbf{U}}$ is the vector of angular strains; $\widetilde{\mathbf{S}}=\left[\begin{array}{lllllll}\widetilde{S}_{1} & \widetilde{S}_{2} & \ldots & \widetilde{S}_{j} & \ldots & \widetilde{S}_{n}\end{array}\right]^{T} ; \widetilde{S}_{j}, \widetilde{U}_{j}$ are adjacent complex of power and voltage of the $j^{\text {th }}$ network node. A small number of variables corresponding to the balancing nodes, in which the $\dot{U}_{j}$ parameters are assumed to be a priori set, are excluded from this system. After separation of real and imaginary components, the final model is formed, which can be written as follows in the general form

$$
\mathbf{F}_{k}\left[\mathbf{V}\left(t_{k}\right), \mathbf{X}\left(t_{k}\right)\right]=\mathbf{0}, k=1 . . m,
$$

where $\mathbf{F}$ is the non-linear vector function; $\mathbf{V}$ is the vector of regulated parameters (independent variables); $\mathbf{X}$ is the vector of non-regulated parameters (dependent variables).

The described simulation technology is implemented within the scope of the Fazonord industrial software package [11], which has passed a large-scale approbation. To verify the adequacy of the simulation, the simulation results were compared repeatedly to instrumental measurements at real facilities. The maximum differences between the calculated and the experimental data did not exceed 3 to $5 \%$, which is a sufficient result for problems of this grade characterized with the presence of inaccuracies in the initial information.

Fazonord software package allows simulating modes of RPSS of various design, for example, RPSS with reinforcing elements used in upgrading of high-speed lines. The following systems may be attributed to such RPSS systems [1]:

- 2x25 kV RPSS with Woodsbridge synchronizing transformers (ST) [12] (Fig. 1);

- RPSS with coaxial cables (Fig. 2) [1].

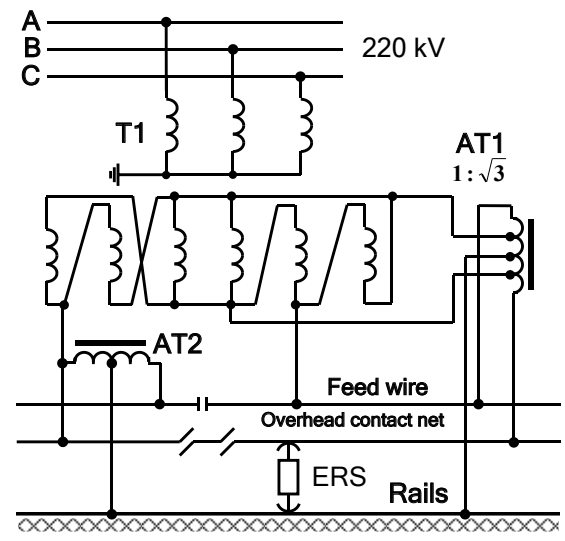

Fig. 1. 2x25 kV RPSS with modified Woodsbridge transformers [12]: AT - automobile transformers; ERS - electrical rolling stock.

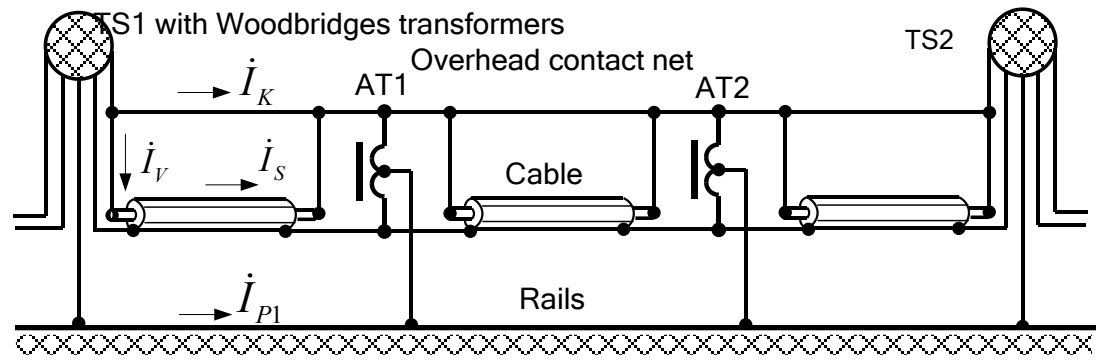

Fig. 2. Layout of the $2 \times 25 \mathrm{kV}$ traction network with modified Woodsbridge transformers and coaxial cables [1]. 
The coaxial cable can be represented by a multi-wire model. This model assumes a relative dielectric permeability of the medium equal to one, therefore, it is possible to reduce the distance between the core and the conductors of the screen to obtain the required equivalent generation of reactive power. With that, the induction of the core-screen loop is changed insignificantly. The required internal diameter of screen $D$ can be calculated from the formula for the capacitance of a cylindrical capacitor:

$$
D=d \exp \left(\frac{2 \pi \varepsilon_{0}}{C}\right)
$$

where $d$ is the core diameter; $C$ is the linear reservoir. See the coordinates of location of current conducting parts of the TN model on Figure 3.

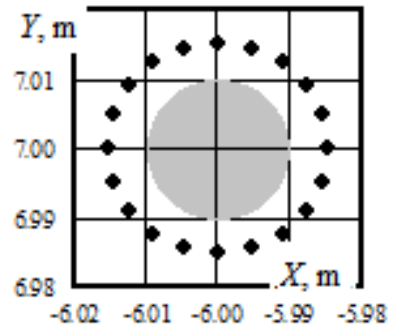

a)

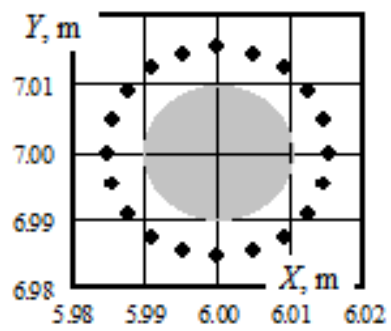

b)

Fig. 3. Coordinates of the model wires: $a$ is the section of the left cable conductors, $b$ is the right cable section.

At the first stage of the simulation, which was performed on the basis of the Fazonord software package, a traditional $2 \times 25 \mathrm{kV}$ traction network of the $85 \mathrm{~km}$ long section of the railroad with three traction substations and $220 \mathrm{kV}$ power supply was considered for movement of four conventional passenger trains with electric VL-65 locomotives and the same number of the Sapsan electric trains $[13,14]$. The average segment speed for the first variant was $60 \mathrm{~km} / \mathrm{h}$, and for the second variant the speed was $230 \mathrm{~km} / \mathrm{h}$. The aforementioned variants of upgrading of the traction network are considered at the second stage.

\section{Simulation results}

See the simulation results in Table 1 and 2 and on Figure 4 to 6.

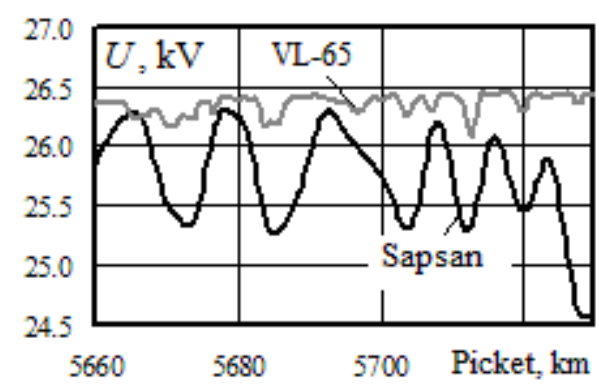

a)

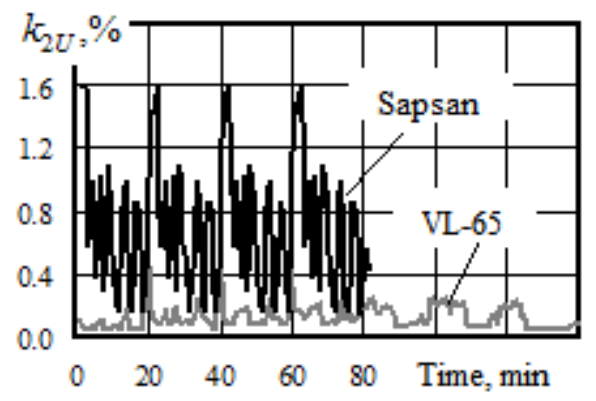

b)

Fig. 4. The voltage on the current collector of the first train (a) and the imbalance factor in the reverse order (b) on the $220 \mathrm{kV}$ buses of TS 2. 


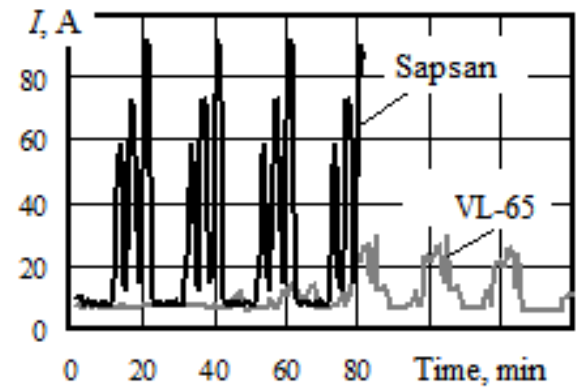

a)

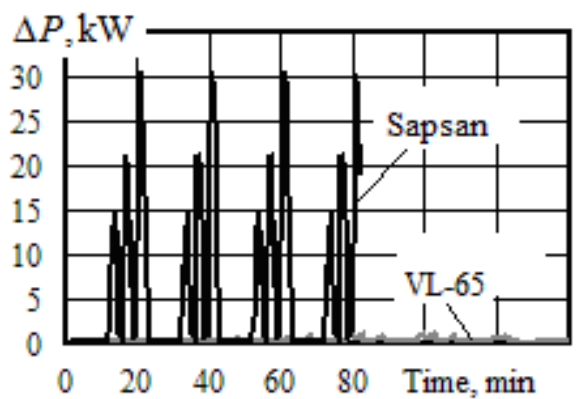

b)

Fig. 5. Currents of the TS-1 contact network feeder (a) and losses of power on the first segment of the contract network (b)

Table 1. Transfers of active and reactive energy $\left(W_{a}, W_{r}\right)$ and losses $\left(\Delta W_{a}\right)$ at the head segment of the feeding overhead power transmission line.

\begin{tabular}{|c|c|c|c|}
\hline Parameter & VL 65 & Sapsan & Difference, $\%$ \\
\hline$\Delta W_{a}, \mathrm{kWh}$ & 232 & 141 & -39 \\
\hline$W_{a}, \mathrm{kWh}$ & 3,000 & 8,120 & 170 \\
\hline$W_{r}, \mathrm{kvar} \cdot \mathrm{h}$ & $-61,100$ & $-32,200$ & 47 \\
\hline
\end{tabular}

Table 2. Summarized indicators.

\begin{tabular}{|c|c|c|c|c|c|c|c|c|c|}
\hline \multirow{2}{*}{$\begin{array}{c}\text { Paramet } \\
\text { er }\end{array}$} & \multicolumn{3}{|c|}{ Minimum } & \multicolumn{3}{c|}{ Average value } & \multicolumn{3}{c|}{ Maximum } \\
\cline { 2 - 10 } & VL 65 & Sapsan & $\begin{array}{c}\text { Difference, } \\
\%\end{array}$ & VL 65 & Sapsan & $\begin{array}{c}\text { Difference, } \\
\%\end{array}$ & VL 65 & Sapsan & $\begin{array}{c}\text { Difference } \\
\%\end{array}$ \\
\hline$k_{2 U}, \%$ & - & - & - & 0.1 & 0.7 & 600 & 0.5 & 1.6 & 220 \\
\hline$U, \mathrm{kV}$ & 26.1 & 24.6 & -5.7 & 26.4 & 25.6 & -3.0 & 26.5 & 26.3 & -0.8 \\
\hline
\end{tabular}

Notes: $k_{2 U}$ is the imbalance coefficient by reverse sequence on $220 \mathrm{kV}$ buses of TS2; $U$ is the voltage on the current collector of the first train.

A high-speed train generates traction loads of much greater magnitude than a conventional passenger train. The currents that flow through the contact wires (Fig.5a) are increased approximately threefold. The growth of traction loads causes reduction in the voltage on the current collectors of electric locomotives (Fig. 4, a), to a significant increase in asymmetry (Fig. 4, b) on high-voltage buses of traction substations, as well as losses in the traction network (Fig. 5, b).

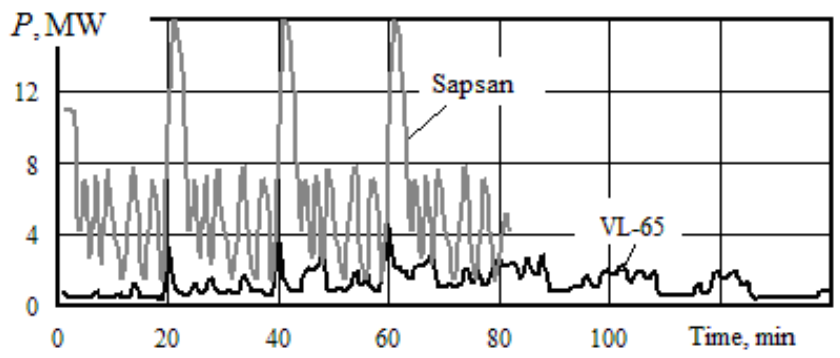

Fig. 6. Active capacity flows in the trunk OPTL 1. 
The increased loads created by trains with Sapsan locomotives cause a significant increase in the active power flow in the trunk overhead power transmission line (Fig. 6). However, the total losses of $\Delta W_{a}$ are reduced due to redistribution of reactive transfers (Table 1).

The results of simulating the movement of high-speed trains in the RPSS equipped with Woodbridge transformers and coaxial cables are summarized in Table 3 and are illustrated in Figures 7, 8.

Table 3. Imbalance in $220 \mathrm{kV}$ buses of TS2 and voltage in the current collector of the train.

\begin{tabular}{|c|c|c|c|c|c|c|}
\hline \multirow{2}{*}{$\begin{array}{c}\text { Indicato } \\
\mathrm{r}\end{array}$} & \multirow{2}{*}{ Parameter } & \multicolumn{3}{|c|}{ Value } & \multicolumn{2}{c|}{ Difference, \% } \\
\cline { 3 - 7 } & & $\mathbf{T}$ & $\mathbf{W}$ & $\mathbf{W}+\mathbf{C}$ & $\begin{array}{c}\text { Between the } \\
\text { poles } \\
\text { 2 and 1 }\end{array}$ & $\begin{array}{c}\text { Between the } \\
\text { poles } \\
3 \text { and } 1\end{array}$ \\
\hline \multirow{3}{*}{$k_{2 U}, \%$} & Average & 0.7 & 0.7 & 0.7 & 0 & 0 \\
\cline { 3 - 7 } & Maximum & 1.6 & 1.6 & 1.4 & 0 & -12.5 \\
\hline \multirow{3}{*}{$U, \mathrm{kV}$} & Minimum & 24.6 & 24.8 & 27.2 & 0.8 & 10.6 \\
\cline { 2 - 7 } & Average & 25.6 & 25.6 & 27.7 & 0 & 8.2 \\
\cline { 2 - 7 } & Maximum & 26.3 & 26.2 & 28.3 & -0.4 & 7.6 \\
\hline
\end{tabular}

Note: $\mathrm{T}-$ traditional $2 \times 25 \mathrm{kV}$ RPSS; $\mathrm{W}-$ RPSS with Woodbridge transformers; $\mathrm{W}+\mathrm{C}-\mathrm{RPSS}$ with Woodbridge transformers and coaxial cables.

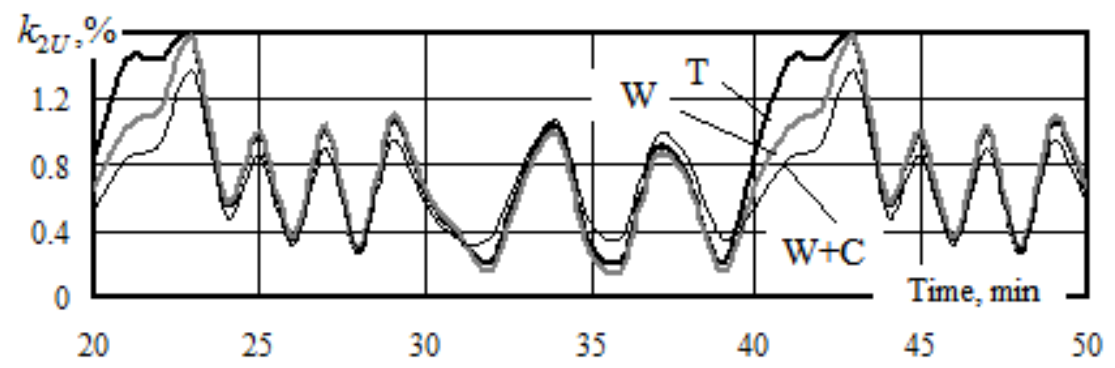

Fig. 7. Imbalance coefficients on reverse order on $220 \mathrm{kV}$ buses of TS 2: $\mathrm{T}-$ traditional $2 \times 25 \mathrm{kV}$ RPSS; W - RPSS with Woodbridge transformers; W+C- RPSS with Woodbridge transformers and coaxial cables.

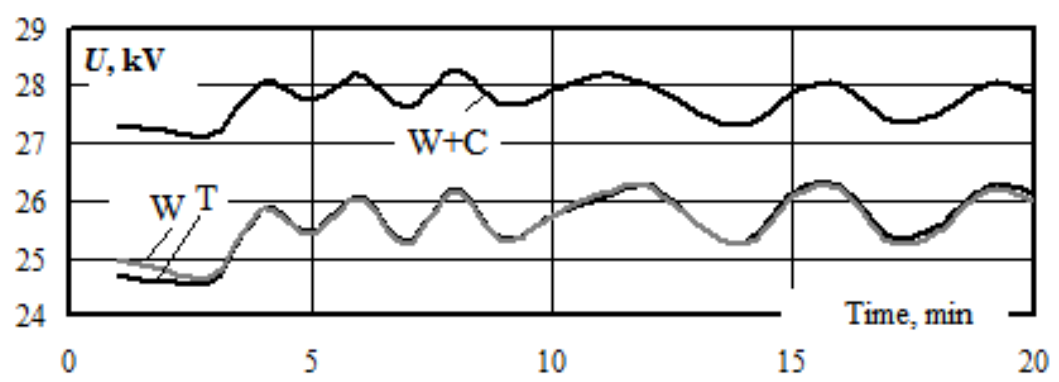

Fig. 8. Voltage on the current collector of the first train. 
The results obtained demonstrate that the use of coaxial cables contributes to a significant increase in the level of voltage on ERS current collectors, which is particularly important for high-speed lines.

Use of modified Woodbridge transformers in $2 \times 25 \mathrm{kV}$ RPSS makes it possible to reduce the imbalance coefficient by the reverse sequence on high voltage buses of traction substations. The biggest positive effects occur in the integrated application of balancing transformers and coaxial cables.

\section{Conclusion}

The results obtained indicate that the problem of simulating modes of traction power systems of high-speed AC railways can be solved on the basis of the methods proposed. The described computer technologies can be used in practice to select the most rational ways to strengthen traction networks. It is expedient to perform further studies in the direction of development of the technologies for simulation of modes of the RPSS equipped with automatic mode regulating means [14 - 17].

\section{References}

1. I.P. Kiselev, L.S. Blazhko, A.T. Burkov, et al., Vysokoskorostnoj zheleznodorozhnyj transport [High-Speed Railway Transport] (UMCZDT, Moscow, 2014). (in Russian)

2. I.P. Kiselev, Zheleznodorozhnyj transport [Journal of Rail Transport], No. 5, 6-7 (2011). (in Russian)

3. B.M. Lapidus, Zheleznodorozhnyj transport [Journal of Rail Transport], No. 9 (2014). (in Russian)

4. V.A. Gapanovich, Zheleznodorozhnyj transport [Journal of Rail Transport], No. 9 (2014). (in Russian)

5. A. Steimel, Electric traction motive power and energy supply. Basics and practical experience (Oldenbourg Industrieverlag, Munchen, 2008).

6. H. Biesenack, E. Braun, G. George, et al., Energieversorgung elektrischer bannen (B.G. Teubner Verlag, Wiesbaden, 2006).

7. A. Ogunsola, A. Mariscotti, Electromagnetic Compatibility in Railways (Springer, 2013).

8. R.J. Hill, Transactions on the Built Environment, Vol. 6 (1994).

9. M. Mandić, I. Uglešić, V. Milardić, Tehnički vjesnik, No. 20, 3 (2013).

10. M.G. Shalimov, G.P. Maslov, G.S. Magay, Sovremennoe sostojanie $i$ puti sovershenstvovanija sistem jelektrosnabzhenija jelektricheskih zheleznyh dorog, [Current state and ways to improve the electric power supply systems for electric railways] (OSTU, Omsk, 2002). (in Russian)

11. V.P. Zakaryukin, A.V. Kryukov, Innovation \& Sustainability of Modern Railway Proceedings of ISMR'2008 (Beijing: China, 2008).

12. Y. Hase, Handbook of power system engineering (John Wiley \& Sons Ltd, 2007).

13. V. Zakaryukin, A. Kryukov, A. Cherepanov, International Scientific Conference Energy Management of Municipal Transportation Facilities and Transport EMMFT 2017 (EMMFT 2017), Advances in Intelligent Systems and Computing, Vol. 692 (Springer, 2017).

14. V.P. Zakarjukin, A.V. Krjukov, I.M. Avdienko, et al., Modern technologies. System analysis. Modeling, No. 3(55) (2017). (in Russian)

15. A. Alsulami, MSc Thesis, Chalmers University of Technology (Goteborg, Sweden, 2014). 
16. A. Pana, Active Load Balancing in a Three-Phase Network by Reactive Power Compensation, in: Power Quality and Monitoring, Analysis and Enhancement (2011).

17. M.M. Saied, Electrical Power Quality and Utilisation, Vol. XVI, No. 1 (2013). 